\title{
Quality of life of depressed and suicidal patients seeking services from traditional and faith healers in rural Kenya
}

Christine W. Musyimi ${ }^{1,2}$, Victoria N. Mutiso', Sameera S. Nayak ${ }^{3}$, David M. Ndetei ${ }^{1,4^{*}}$, David C. Henderson ${ }^{5,6}$ and Joske Bunders ${ }^{2}$

\begin{abstract}
Background: In rural Kenya, traditional and faith healers provide an alternative pathway to health care, including mental health care. However, not much is known about the characteristics of the populations they serve. The purpose of this study was to determine the relationship between depression, suicidal ideation, and socio-demographic variables with Quality of Life (QoL) indicators in a sample seeking mental health services from traditional and faith healers in rural Kenya. Understanding QoL in this sample can help develop mental health policy and training to improve the well-being of this population.
\end{abstract}

Method: This was a cross-sectional epidemiological survey $(n=443)$ conducted over a period of 3 months among adult patients seeking care from traditional and faith healers in rural Kenya. Data were collected using the Beck Depression Inventory II (BDI-II), Beck Scale for Suicide Ideation (BSS) and WHO Quality of Life Survey- BREF (WHOQOL-BREF), and analyzed using correlation analyses, parametric tests, and regression analyses.

Results: Increasing levels of depression were associated with lower QoL among patients seeking care from traditional and faith healers. BSS scores were significantly negatively correlated with overall, physical, psychological, and environmental QoL, $p<.05$. There was a statistically significant difference between mean scores for overall QoL between depressed $(M=2.35, S D=0.76)$ and non-depressed participants $(M=3.03, S D=0.67), t(441)=8.899, p<.001$. Overall life satisfaction for depressed participants $(M=2.23, S D=0.69)$ was significantly lower than non-depressed participants. Regression analyses indicated that depression, suicidal ideation, and being married predicted lower overall QoL controlling for other variables. Post hoc tests and subgroup analysis by gender revealed significant differences for females only. Depression, and older age predicted lower life satisfaction whereas being self-employed predicted higher life satisfaction, when controlling for other variables.

Conclusion: This study sheds light on correlates of QoL in depressed and non-depressed patients in rural Kenya. Evidence suggests that traditional and faith healers treat patients with a variety of QoL issues. Further research should focus on understanding how these issues tie into QoL, and how these healers can target these to improve care.

Keywords: Kenya, Traditional healer, Faith healer, Depression, Suicide, Quality of life

\footnotetext{
* Correspondence: dmndetei@amhf.or.ke

${ }^{1}$ Africa Mental Health Foundation, Nairobi, Kenya

${ }^{4}$ University of Nairobi, Nairobi, Kenya

Full list of author information is available at the end of the article
} 


\section{Background}

Low and middle income countries (LMICs) often have overburdened mental health systems with limited resources, capacity, and infrastructure [12]. At the same time the global burden of disease of mental illness is on the rise, disproportionally affecting LMICs, where the mental health treatment gap is large and expanding $[35,63]$. In this context, individuals in LMICs often seek mental health services through alternative pathways of care in the informal sector, such as traditional and faith healers [12]. In Kenya for example, there is a tremendous scarcity of mental health services with less than 100 psychiatrists practicing in the country, which might compel individuals to seek care from healers who are more readily accessible $[33,42]$. Furthermore, there are other social and cultural factors that make these providers more favorable and acceptable to the community than physicians practicing western medicine [2]. Studies from Africa suggest that traditional and faith healers play a key role in providing services to a vast number of mentally ill patients [12, 13, 44]. However, not much is known about patients who seek care from these sources.

In Kenya, although not formally recognized, traditional and faith healers offer a parallel system of mental health-care [42]. A recent mixed-methods study in three informal urban settlements around Nairobi, Kenya found that these healers often treat patients with mental illness using a mixture of counseling, herbal remedies, consultations with the spiritual world, and home-visits to cleanse the environment of bewitching forces [44]. The healers in this sample were frequented by individuals with a variety of mental illnesses ranging from common mental illness such as depression and anxiety to more severe forms of mental illness such as schizophrenia [44]. Depression and current suicidal behavior were co-occurring in this sample, which is unsurprising but troubling, given that suicide is a leading cause of mortality worldwide and is frequently associated with depression $[16,40,44,67]$. Although this study sheds some light on the types of disorders treated in the informal sector in Kenya, there is relatively little information known about the quality of life (QoL) of individuals seeking care for mental illness in this sector.

Despite the fact that health care research has historically approached health outcomes from a morbidity and mortality perspective, research has shown that QoL is a meaningful tool that can be used to predict disease outcomes and patient well-being [19, 41]. QoL is an important construct that provides an indication of an individual's subjective well-being in relation to their socio-cultural context and value systems [45, 46]. Understanding the factors that are related to QoL in depressed and suicidal patients is crucial for the development of public health policies that can improve overall health outcomes. If research can accurately capture the domains of QoL that are being affected by depression severity and suicidal ideation, then this presents a valuable opportunity to develop well-informed interventions that specifically target these domains. Unfortunately, the research on this subject in Kenya is scarce.

This is the first study, to our knowledge, that has attempted to capture differences in QoL measures between depressed and non-depressed patients in the informal health care sector. There is a dearth of research in Africa, particularly Kenya specifically related to quality of life for individuals with depression. As Kenya moves towards a better integration of mental health into primary health care $[30,31]$, it is necessary to mobilize the informal and formal sectors to work in partnership as suggested through a recent study in rural Kenya [47]. Since the data on the treatment-seeking population in the informal sector is limited, it is essential to first gather a holistic understanding of this population in order to identify whether their characteristics are similar or dissimilar to those seeking care from formal psychiatric service centers. Thus results from this assessment study can inform the development of interventions targeted to the needs of this population and aimed at improving specific domains of quality of life. The aim of this study is to determine the relationship between depression, suicidal ideation, and socio-demographic variables with QoL indicators in a sample seeking mental health services from traditional and faith healers in rural Kenya.

\section{Methods}

\section{Participants and procedures}

This was part of a longitudinal study that involved the identification of patients with depression and follow-up over a period of 3 months, after baseline assessments in Makueni County, one of the 47 counties in Kenya. A total of 4081 patients who sought care from traditional and faith healers in four regions of Makueni County between September 2014 to November 2014 were screened for depression by traditional and faith healers [46] in order to receive psychosocial interventions by the same healers. Community Health Volunteers (CHVs) were then invited to screen patients for depression in order to assess the severity and frequency of symptoms of depression as well as to measure the QoL of patients. Permission was sought from traditional and faith healers and their patients at the healers' shrines/offices before data collection. Only 443 participants (71.7\% female) with a mean age of $48.2(\mathrm{SD}=16.7)$ agreed to undergo another assessment by a different provider (CHV), translating to a $10 \%$ participation rate. The low number was attributed to patients' lack of sufficient time for a second 
assessment, over-reliance, confidence and trust for their healers, a feeling of wellness especially if their healer confirmed a negative depression score and a first of a kind study to be conducted in the region, especially for a condition perceived to be a symptom related to laziness or a physical condition (for instance headaches, sleep problems, fatigue, reduced or increased appetite). Interestingly, $34 \%$ of patients who were screened positive by the healer and $4 \%$ of those who were found to be negative agreed to be reassessed. The huge difference (30\%) could have been attributed by the depressed participants' desire to receive interventions. Those who agreed to participate to be screened by $\mathrm{CHVs}$ were once again explained the procedures, confidentiality measures, benefits versus risks and the free will to decline or withdraw from the study without incurring any costs or losing any benefits.

Participants independently completed self-report questionnaires (described below under measures). A community health volunteer was present to provide support and answer any questions. In order to maintain confidentiality, each participant was given a unique identification code. A total of 316 participants met the criteria for a depression diagnosis.

\section{Ethics and informed consent}

Kenyatta National Hospital/University of Nairobi Ethics Review Committee provided ethical approval for this study. All patients who agreed to be screened by a community health volunteer provided informed consent to participate in the study.

\section{Measures}

\section{Socio-demographic Information}

Data on the socio-demographic characteristics of the participants were collected including age, gender, religious belief, highest level of education, marital status and type of employment.

\section{Beck depression inventory II (BDI-II)}

The BDI-II [5] is a 21-item self-report scale measuring presence and severity of depression symptomatology. The BDI-II has four response options from 0 to 3, with 3 representing greater severity. In this study, "don't know" and "refused to answer" were coded as 7 and 8 respectively. The BDI-II total score was calculated by summing up the response options; codes 7 and 8 were excluded from the total score calculation. BDI-II total scores range from 0-63 with a higher score representing increased severity of symptoms. The clinical cut-offs are as follows: 1) 1-10, normal ups and downs; 2) 11-16, mild mood disturbance; 3) 17-20 borderline depression; 4) 21-30, moderate depression; 5) 31-40, severe depression; 6) over 40 , extreme depression. In order to characterize the sample into binary groups, BDI-II scores were re-coded into (1) no depression (range $0-20$ ) and (2) yes depression (range 21-63). The BDI-II has high internal consistency, Cronbach's $\alpha=.92$ [5]. It has been previously used in Kenya and in other non-western countries [23, 36, 49, 62]. It has been shown to be an effective tool for depression screening in Kenya [49].

\section{Beck scale for suicide ideation (BSS)}

The BSS [4] is a 21-item self-report scale designed to detect the participant's desire, attitudes, behaviors, and plans to commit suicide [11]. The first 19 items of the scale are coded with 3 response options from 0 to 2 . The first five questions are used to screen for suicidal ideation (SI); if an individual responds affirmatively to any one of these items, the remaining 14 items are then administered. The sum of the first 19 items is calculated to create a total score ranging from 0 to 38 . Higher score indicates higher SI. The last items assess incidence and factors related to previous suicide attempts. Internal consistency of the BSS has been shown to be high, Cronbach's $\alpha=.95$ [59]. The BSS has been used with a variety of populations $[15,28,32,37,51]$. Although it has been used in neighboring Uganda, it has not been used in Kenya prior to this study [50].

\section{WHO quality of life survey- BREF (WHOQOL-BREF)}

The WHOQOL-BREF [66] is a 26-item scale assessing an individual's QoL profile. The WHOQOL-BREF assesses four domains: physical, psychological, social relationships, and environment. Furthermore, there are two questions assessing self-reported overall QoL and life satisfaction. Item responses are coded from 1 to 5; items 3, 4, and 26 are reverse coded. Higher scores on each domain indicate a higher quality of life. Mean score of items in each domain is used to calculate a domain score. These scores are then multiplied by 4 in order to make WHOQOL-BREF scores comparable to the longer quality of life tool, WHOQOL-100. Cases with greater than $20 \%$ missing data from a domain are automatically excluded from analyses. There were no such cases in this dataset. Internal consistency is acceptable with Cronbach's $\alpha>.70$ for physical, psychological, and environment domains but 0.68 for social relationships [56]. The WHOQOL-BREF has been adapted and used crossculturally in a variety of countries including Kenya, Nigeria, Brazil, Taiwan and Rwanda $[1,6,22,34,48,68]$. The internal consistency ranged from $0.76-0.85$ for the Brazilian version and $0.70-0.77$ for the Taiwanese version $[6,68]$. Similarly, some countries such as Israel, Turkey and Romania have reported marginal Cronbach's $\alpha$ in the environmental domain [56]. Changes in Cronbach's $\alpha$ have not been reported in other studies [1, 22, 34, 48]. Furthermore, this tool is derived from the WHOQOL-100 which 
was developed as part of a large cross-cultural initiative, and hence is likely to provide a relatively robust measure of QoL in different settings [52]. Its equivalence has also been evaluated with a lot of rigor and therefore has the potential to provide valid scores for comparison in different settings [9].

\section{Data analysis}

Double data entry was carried out using IBM SPSS 23. Data was double entered, compared for any discrepancies, corrected and analyzed using the same software. Descriptive statistics were run to determine the demographics of the sample. Independent samples t-tests and Chi-square tests of independence were run to determine if there were significant group differences between depressed and non-depressed participants on these socio-demographic variables. Pearson's correlation coefficient was performed to determine correlations between scores on the BDI-II, BSS, and WHOQOL-BREF.

Independent samples t-tests were also carried out to determine if there were statistically significant differences on QoL measures for depressed and non-depressed participants. This was repeated to establish differences on QoL measures between participants with SI as compared to those without SI. Multiple regression analyses were then used to determine predictors of QoL for participants in this sample. Dummy variables were created for level of education, employment status, and marital status. A model was run with overall self-reported QoL as the outcome variable and age, gender, depression diagnosis, level of education, employment status, marital status, and SI as predictor variables. This model was then run with life satisfaction, physical QoL, social QoL, psychological QoL, and environmental QoL as outcome variables respectively. Variance inflation factor (VIF) was used to assess multicollinearity between predictor variables in the models. No issues with multicollinearity were found (VIF not larger than 10). Missing data in the analyses were excluded on a case-wise basis. There was no missing data for the BDI-II whereas . $2 \%$ of BSS had missing data. In regards to the WHOQOL-BREF, there was .5 and .2\% missing data for domain 2 (psychological QoL) and domain 3 (social relationships QoL) respectively, while domains 1 (physical QoL) and 4 (environmental QoL) had no missing data. Statistical significance was set at $p<.05$.

\section{Results}

Table 1 includes the socio-demographic characteristics of the sample. Based on clinical cutoffs for the BDI-II, $71.3 \%$ of the sample had depression while $28.7 \%$ did not. Mean SI was low $(M=.88, S D=3.837) .94 .1 \%$ of the sample had no SI on BSS, 5.9\% had some SI (endorsed one or more items). Of the depressed sample, $7.9 \%$ endorsed SI on the BSS (endorsed one or more items) compared with $0.8 \%$ of the non- depressed sample. Significant differences were found between depressed and non-depressed participants in employment status and SI, $p<.001$. Furthermore, participants in each group differed significantly in their choice of healer for treatment, $p<.001$. No other significant differences were found between groups on demographic variables.

Pearson's correlation was carried out between BDI-II scores, BSS scores, WHOQOL-BREF domain scores, and WHOQOL-BREF overall quality and satisfaction scores. Results were in line with previous studies indicating that depression and SI are correlated, and that depression is negatively related to QoL measures, $p<.001[27,53]$. A surprising finding indicated that although BSS scores were significantly negatively correlated with overall, physical, psychological, and environmental QoL $(p<.01)$, they were not significantly related to overall life satisfaction $(p=.074)$ and the quality of social relationships $(p=.349)$. Therefore, endorsing SI was linked to reductions in certain domains of QoL, but not all.

There was a statistically significant difference between mean scores for overall QoL between depressed $(M=2.35, S D=0.76)$ and non-depressed participants $(M=3.03, S D=0.67), t(441)=8.899, p<.001$. Overall life satisfaction for depressed participants $(M=2.23$, $S D=0.69)$ was significantly lower than non-depressed participants $(M=2.94, S D=0.77), t(427)=9.289, p<.001$. Furthermore, depressed participants had significantly lower scores for each of the WHOQOL-BREF domainspecific items than non-depressed participants, $p<.001$.

In line with previous research, depressed participants had much higher SI $(M=1.23, S D=4.50)$ than non-depressed participants $(M=0.008, \quad S D=0.09)$, $t(440)=-3.063, p=.002$. Mean scores for overall QoL between suicidal ideating $(M=2.12, S D=1.14)$ and non-suicidal ideating participants $(M=2.57, S D=0.76)$ were lower for suicidal participants, $t(440)=2.855, p=.005$. Furthermore, suicidal ideating participants had significantly lower scores for each of the physical $(p<.001)$, psychological $(p=.007)$, and environmental $(p=.010)$ WHOQOL-BREF domain-specific items than nonsuicidal ideating participants. Overall life satisfaction and social relationships QoL were not significantly different between suicidal and non-suicidal ideating participants, $p=.079$ and $p=.102$ respectively.

Predictors included in the regression model were age, gender, level of education, marital status, employment status, depression status, and SI. Age, gender, level of education, marital status, and employment status were included based on previous research, indicating their impact on QoL [3, 22, 25, 34]. Depression and SI were included since they were related to QoL in univariate analyses. This model was run separately with each QoL indicator as an outcome variable. 
Table 1 Socio-demographic characteristics of the sample

\begin{tabular}{|c|c|c|c|c|}
\hline Variable & Depressed $(n=316)$ & Non-depressed $(n=127)$ & Total $(n=443)$ & Group Differences \\
\hline \multicolumn{5}{|l|}{ Type of healer (\%) } \\
\hline Traditional healer & $109(34.5)$ & $1(0.8)$ & $110(24.8)$ & \multirow[t]{2}{*}{$X^{2}(1, n=443)=55.142, p<.001$} \\
\hline Faith healer & $207(65.5)$ & $126(99.2)$ & $333(75.2)$ & \\
\hline Mean age (SD) & $48.0(17.0)$ & $48.8(15.9)$ & $48.2(16.7)$ & $\mathrm{t}(441)=.490, p=.624$ \\
\hline \multicolumn{5}{|l|}{ Gender (\%) } \\
\hline Male & $90(28.5)$ & $38(29.9)$ & $128(28.9)$ & \multirow[t]{2}{*}{$x^{2}(1, n=443)=.091, p=.762$} \\
\hline Female & $226(71.5)$ & $89(70.1)$ & $315(71.1)$ & \\
\hline \multicolumn{5}{|l|}{ Religion (\%) } \\
\hline Catholic & $64(20.3)$ & $32(25.2)$ & $96(21.7)^{a}$ & \multirow[t]{5}{*}{$x^{2}(4, n=442)=6.614, p=.158$} \\
\hline Protestant & $234(74.3)$ & $86(67.7)$ & $320(72.2)^{a}$ & \\
\hline Muslim & $1(0.3)$ & 0 & $1(0.2)^{a}$ & \\
\hline African Traditional Religion & $3(1.0)$ & $5(3.9)$ & $8(1.8)^{\mathrm{a}}$ & \\
\hline No official religion & $13(4.1)$ & $4(3.1)$ & $17(3.8)^{\mathrm{a}}$ & \\
\hline \multicolumn{5}{|l|}{ Level of education (\%) } \\
\hline No formal education & $85(27.2)$ & $35(27.6)$ & $120(27.3)^{b}$ & \multirow[t]{3}{*}{$x^{2}(2, n=440)=2.145, p=.342$} \\
\hline Primary & $196(62.6)$ & $73(57.5)$ & $269(61.1)^{b}$ & \\
\hline Secondary & $32(10.2)$ & $19(15.0)$ & $51(11.6)^{b}$ & \\
\hline \multicolumn{5}{|l|}{ Marital Status (\%) } \\
\hline Single & $32(10.2)$ & $19(15.0)$ & $51(11.6)^{d}$ & \multirow[t]{3}{*}{$x^{2}(2, n=441)=2.406, p=.300$} \\
\hline Divorced/Separated & $72(22.9)$ & $31(24.4)$ & $103(23.4)^{d}$ & \\
\hline Married/Cohabiting & $210(66.9)$ & $77(60.6)$ & $287(65.1)^{d}$ & \\
\hline \multicolumn{5}{|l|}{ Employment Status (\%) } \\
\hline No employment & $159(50.3)$ & $86(70.5)$ & $245(55.9)^{c}$ & \multirow[t]{3}{*}{$X^{2}(2, n=438)=19.974, p<.001$} \\
\hline Self Employed & $125(39.6)$ & $21(17.2)$ & $146(33.3)^{c}$ & \\
\hline Employed & $32(10.1)$ & $15(12.3)$ & $47(10.7)^{c}$ & \\
\hline Suicidal Ideation (\%) & $25(7.9)$ & $1(0.8)$ & $26(5.9)^{a}$ & $x^{2}(1, n=442)=8.356, \boldsymbol{p}=.004$ \\
\hline
\end{tabular}

${ }^{\mathrm{a}} n=442 ;{ }^{\mathrm{b}} n=440 ;{ }^{c} n=438 ;{ }^{\mathrm{d}} n=441$

Bold are significant values

Table 2 demonstrates the results of the regression analyses for overall QoL and life satisfaction. Significant regression equations were found for both models, $p<.001$. It appears that depression diagnosis, marital status, and SI significantly predict overall QoL, when controlling for covariates. Having a depression diagnosis and SI predict lower overall QoL. Furthermore, being married also predicts lower overall QoL when compared to being single. Life satisfaction in this sample was strongly predicted by age, depression diagnosis, and employment status. Older age and a positive depression diagnosis predicted lower life satisfaction whereas being selfemployed predicted higher life satisfaction, when controlling for other variables in the model.

Table 3 shows the results of the regression analyses for each of the four QoL domains measured; physical, psychological, social relationships, and environmental. Significant regression equations were found for each model, $p<.001$. Depression diagnosis predicted a lower QoL in each of the four domains, $p<.001$. Furthermore, older age predicted lower physical QoL but higher psychological QoL. SI was related to lower physical QoL; however, it did not affect any of the other domains. Thus it appears that a depression diagnosis is the most consistent predictor of lowered QoL, across the four domains measured, after controlling for age, gender, level of education, marital status, employment status, and SI.

\section{Discussion}

Present research in this population is limited, with a lack of data on the effects of depression and SI on QoL. This study sought to address this gap by elucidating the relationship between depression, SI, and relevant sociodemographic constructs with QoL in a treatmentseeking sample in rural Kenya. 
Table 2 Multiple regression analyses for overall QoL and life satisfaction as outcome variables

\begin{tabular}{|c|c|c|c|c|c|c|c|c|}
\hline \multirow[b]{3}{*}{ Predictors } & \multicolumn{8}{|c|}{ Outcome Variables } \\
\hline & \multicolumn{4}{|c|}{ Overall Quality of Life $F(10,421)=9.984, p<.001$} & \multicolumn{4}{|c|}{ Life Satisfaction $F(10,407)=10.276, p<.001$} \\
\hline & $\beta$ & SE & $\mathrm{t}$ & $p$ & $\beta$ & SE & $\mathrm{t}$ & $p$ \\
\hline Age & -.004 & .002 & -1.889 & 0.60 & -.005 & .002 & -2.028 & .043 \\
\hline Gender & -.016 & .080 & -.198 & .843 & -.083 & .079 & -1.051 & .294 \\
\hline Depression Diagnosis & -.697 & .080 & -8.654 & $.000^{*}$ & -.739 & .081 & -9.121 & .000 \\
\hline \multicolumn{9}{|l|}{ Level of education } \\
\hline Primary & -.058 & .089 & -.646 & .519 & .011 & .090 & .125 & .900 \\
\hline Secondary & .002 & .135 & .017 & .986 & .215 & .136 & 1.587 & .113 \\
\hline \multicolumn{9}{|l|}{ Marital Status } \\
\hline Divorced/Separated & -.147 & .135 & -1.085 & .278 & .225 & .136 & 1.656 & .098 \\
\hline Married/Cohabiting & -.252 & .115 & -2.195 & $.029^{*}$ & -.035 & .116 & -.306 & .760 \\
\hline \multicolumn{9}{|l|}{ Employment Status } \\
\hline Self Employed & .208 & .081 & 2.579 & $.010^{*}$ & .167 & .081 & 2.074 & $.039^{*}$ \\
\hline Employed & .019 & .121 & .158 & .875 & .104 & .120 & .873 & .383 \\
\hline \multirow[t]{2}{*}{ Suicidal Ideation } & -.021 & .009 & -2.307 & $.022^{*}$ & -.008 & .009 & -.811 & .418 \\
\hline & \multicolumn{4}{|l|}{$\mathrm{R}^{2}=.192$} & \multicolumn{4}{|c|}{$R^{2}=.202$} \\
\hline
\end{tabular}

${ }^{*} p<.05$

Bold are significant values

Findings from this sample indicate that depression significantly and adversely impacts all aspects of QoL. These results are consistent with research that has demonstrated a similar relationship between depression and QoL variables [53]. Kenya has limited formal psychiatric infrastructure, and hence traditional and faith healers are able to access a wider range of patients in remote locations, who might ordinarily lack access to care $[33,42,44]$. Therefore, traditional and faith healers are in a unique position to provide intervention services for depression which could result in improving the QoL of individuals in these rural communities. To our knowledge, there are no empirical studies investigating the effects of depression-interventions on QoL indicators in

Table 3 Multiple regression analyses for domain-specific QoL as outcome variables

\begin{tabular}{|c|c|c|c|c|c|c|c|c|}
\hline \multirow[b]{3}{*}{ Predictors } & \multicolumn{8}{|c|}{ Outcome Variables } \\
\hline & \multicolumn{2}{|c|}{$\begin{array}{l}\text { Physical QoL F(10,421) } \\
=6.025, p<.001\end{array}$} & \multicolumn{2}{|c|}{$\begin{array}{l}\text { Psychological QoL F(10,419) } \\
=9.807, p<.001\end{array}$} & \multicolumn{2}{|c|}{$\begin{array}{l}\text { Social QoL F(10,420) } \\
=6.975, p<.001\end{array}$} & \multicolumn{2}{|c|}{$\begin{array}{l}\text { Environmental QoL } F(10,421) \\
=8.625, p<.001\end{array}$} \\
\hline & $\bar{\beta}$ & $p$ & $\bar{\beta}$ & $p$ & $\bar{\beta}$ & $p$ & $\bar{\beta}$ & $p$ \\
\hline Age & -.012 & $.013^{*}$ & .019 & $.004^{*}$ & .008 & .308 & .002 & .728 \\
\hline Gender & .010 & .952 & .011 & .962 & -.195 & .490 & -.360 & .089 \\
\hline Depression Diagnosis & -1.041 & $.000^{*}$ & -1.888 & $.000^{*}$ & -2.095 & $.000^{*}$ & -1.819 & $.000^{*}$ \\
\hline \multicolumn{9}{|l|}{ Level of education } \\
\hline Primary & .067 & .725 & .335 & .188 & .285 & .366 & .183 & .438 \\
\hline Secondary & -.142 & .625 & .286 & .463 & -.054 & .910 & .218 & .543 \\
\hline \multicolumn{9}{|l|}{ Marital Status } \\
\hline Divorced/Separated & .155 & .592 & .434 & .263 & .648 & .176 & .410 & .252 \\
\hline Married/Cohabiting & -.214 & .383 & -.253 & .443 & .141 & .727 & .273 & .369 \\
\hline \multicolumn{9}{|l|}{ Employment Status } \\
\hline Self Employed & .142 & .410 & .114 & 620 & -.300 & .294 & .133 & .534 \\
\hline Employed & .224 & .385 & .269 & .438 & -.642 & .133 & -.151 & .637 \\
\hline \multirow[t]{2}{*}{ Suicidal Ideation } & -.051 & $.010^{*}$ & -.038 & .152 & .012 & .709 & -.035 & .155 \\
\hline & \multicolumn{2}{|l|}{$R^{2}=.125$} & \multicolumn{2}{|l|}{$R^{2}=.190$} & \multicolumn{2}{|l|}{$R^{2}=.142$} & \multicolumn{2}{|l|}{$R^{2}=.170$} \\
\hline
\end{tabular}

${ }^{*} p<.05$

Bold are significant values 
Kenya. However, research from other countries suggests that this might represent a feasible pathway to enhance one of the most important components of health care, QoL [55, 58, 64].

Suicidal ideation was also related to differences in QoL in this sample. Individuals with SI tend to have lower QoL on all domains of this construct [24]. However, in this sample SI predicted decreases in overall QoL and physical QoL but not in the other domains measured. This is in line with a recent study which found that suicidal ideation is related to reductions in physical QoL over time [18]. Physical QoL items in the WHOQOLBREF are related to daily activities, fatigue, pain, dependence on pharmaceuticals, sleep, mobility, and work capacity [66]. SI has been linked to sleep disturbances, physical pain, and exhaustion/fatigue [10, 14, 29, 54, 57, 61, 65]. Since these facets of functioning are most affected by SI, this could explain the reduced QoL response in this domain for individuals with SI. Findings from this sample suggest that interventions tailored to reduce suicidal ideation should also incorporate methods to alleviate some of the somatic symptoms that might accompany it, such as fatigue. By addressing this symptomology, interventions might make gains both in reduced SI and in improved physical QoL.

Our study indicated that there were interesting sociodemographic characteristics that affected QoL; specifically, age, employment status, and marital status. Increasing age in this sample predicted lower self-reported overall QoL and lower physical QoL but higher psychological QoL. Decreases in physical QoL have been documented in other studies that have examined changes in quality of life over the lifespan [26]. This could be related to overall declining health status with age, which is correlated with reductions in QoL [26]. Moreover, overall decreases in QoL with ageing might be linked to a variety of internal and external factors such as functional disabilities, financial burdens, social isolation, and loneliness $[20,60]$. The increases in psychological QoL with increasing age seen in this sample might be associated with more realistic goal-setting and lower standards and aspirations in older cohorts [17]. Research has also shown that older cohorts tend to have less positive and negative affect and emotions, leading to a more stable psychological profile [17]. Moreover, there is evidence to suggest that happiness as a construct has a U-shaped curve, with younger and older cohorts demonstrating higher levels than those in the middle age range [8]. It is possible that the older participants in our cohort fit into this global trend and hence perceive their psychological QoL as higher than their younger counterparts because of heightened happiness. At the same time, it is important to delineate that happiness and QoL are not necessarily the same construct, although they might be related. These results suggest that interventions for depression should factor in addressing somatic complaints for older patients and addressing overall happiness and well-being complaints for middle-aged cohorts. These analyses thus shed light on how depression interventions should be tailored in an age-specific manner in order to be most effective.

Post hoc tests were performed to determine the differences between employment status and depression levels using adjusted residuals to estimate Chi-square value for individual cell and subsequent $P$-values and applying Bonferroni's correction [21]. Results indicated that the significant differences in depression levels were only found among the self employed and unemployed groups. No significant difference were found among the employed $(p=0.509)$. Furthermore, being self-employed in this sample predicted higher self-reported life satisfaction as compared to being employed or to not working at all. Self-employment is consistently related to both higher job satisfaction and overall life satisfaction [7, 39]. This might be an important avenue to target through livelihoods-based interventions. Interventions directed at promoting entrepreneurship and self-employment could serve as a pathway to foster greater job satisfaction and overall life satisfaction that could in turn achieve a sustainable solution to impoverished populations. However, since this was a cross-sectional study, it is impossible to determine whether symptoms of depression in participants surfaced prior to or during employment.

Lastly, being married or cohabiting with a partner in this sample predicted lower overall self-reported QoL. Our results contradict a recent study in South Korea which found that married participants generally had a higher QoL than other groups [25]. Furthermore, marriage has traditionally been associated with better mental health possibly due to higher rates of social and practical support $[3,38,43]$. However, post hoc tests using Least Significant Difference (LSD) and subgroup analysis by gender revealed significant differences for females only. Even though this might have been accounted for by the higher numbers, further research is needed to establish the validity of this claim in this population.

\section{Implications}

The findings from this study suggest that there is great scope for traditional and faith healers to provide evidence-based care to the community and improve QoL indicators. It appears that in addition to mental illness (depression and SI), marital status, employment status, and age, potentially play important roles in regulating QoL. However, the cross-sectional nature of this study limits interpretations on the causality and reasons for the effects of these predictor variables. Future research would benefit from a focus on longitudinal studies investigating the role of marital quality, age-related physical and psychosocial factors, and changes in 
employment-status on depressive symptomology and QoL indicators. These results can then be used to develop targeted interventions that address deficits in these indicators to indirectly improve QoL for individuals in rural communities.

\section{Limitations}

There is limited data on the validity and reliability of the measurement tools (BDI-II, BSS, WHOQOL-BREF) in this specific population, and thus results must be interpreted with caution. Furthermore, the crosssectional nature of this study makes it impossible to infer causality.

\section{Conclusions}

Previous literature has shown that healers in the informal sector treat a variety of mental disorders including affective disorders, psychosis, anxiety disorders, substance use disorders, schizophrenia, and personality disorders [44]. This study builds upon this work to shed light on correlates of QoL in depressed and non-depressed patients in rural Kenya. Evidence suggests that traditional and faith healers provide services for individuals suffering from numerous issues related to QoL. Future research is required to determine how these healers can incorporate care for these issues into their treatment modules.

\section{Acknowledgements}

This work was supported by Grand Challenges Canada (GCC) (grant number S5_0415-01) to the first author (PhD candidate, VrijeUniversiteit) and implemented by the Africa Mental Health Foundation under the supervision of the corresponding author. CWM conceived, designed the study, wrote the protocol and provided guidance on manuscript writing and revisions to the first draft. SSN wrote the first draft of the manuscript. All supervisors (DMN, $\mathrm{DCH}$, and JB) were involved in manuscript review and approving the final version of the manuscript. VNM played a key role in coordinating data collection, data entry and cleaning, analysis and interpretation of data and provided critical revisions to the manuscript. The corresponding author had full access to all the data in the study and had final responsibility for the decision to submit the manuscript for publication. GCC had no role in the study design, data collection, analysis, interpretation, writing of the manuscript or in the decision to submit the manuscript for publication.

\section{Funding}

This work was supported by Grand Challenges Canada (GCC) (grant number S5_0415-01).

Availability for data and materials

Available on request from the corresponding author.

\section{Authors' contributions}

All authors were instrumental in the research process. All authors read and approved the final manuscript.

\section{Competing interests}

The authors declare that they have no competing interests.

\section{Consent for publication}

Not applicable

\section{Ethics approval and consent to participate}

The procedures contributing to this work comply with the ethical standards of the relevant national and institutional committees on human experimentation and with the Helsinki Declaration of 1975, as revised in 2008. The ethical approval for this study was provided by Kenyatta National Hospital/University of Nairobi Ethics Review Committee. Informed consent was obtained from all individuals included in the study.

\section{Publisher's Note}

Springer Nature remains neutral with regard to jurisdictional claims in published maps and institutional affiliations.

\section{Author details}

${ }^{1}$ Africa Mental Health Foundation, Nairobi, Kenya. ${ }^{2}$ Vrije Universiteit, Amsterdam, Netherlands. ${ }^{3}$ Columbia University, New York, USA. ${ }^{4}$ University of Nairobi, Nairobi, Kenya. ${ }^{5}$ Boston University School of Medicine, Boston, USA.

${ }^{6}$ Harvard Medical School, Boston, USA.

Received: 10 November 2016 Accepted: 13 April 2017

Published online: 08 May 2017

\section{References}

1. Adewuya AO, Afolabi MO, Ola BA. Relationship between depression and quality of life in persons with HIV infection in Nigeria. Int J Psychiatry Med. 2008:38(1):43-51. doi:10.2190/PM.38.1.d.

2. Ae-Ngibise K, Cooper S, Adiibokah E, Akpalu B, Lund C, Doku V, The Mhaap Research Programme Consortium. Whether you like it or not people with mental problems are going to go to them": a qualitative exploration into the widespread use of traditional and faith healers in the provision of mental health care in Ghana. Int Rev Psychiatry. 2010;22(6):558-67. doi:10. 3109/09540261.2010.536149.

3. Akhtar-Danesh N, Landeen J, Sartorius N, Ustun T, Lecrubier Y, Wittchen H, et al. Relation between depression and sociodemographic factors. Int J Ment Health Syst. 2007:1(1):4. doi:10.1186/1752-4458-1-4

4. Beck A, Steer R. Manual for the Beck scale for suicide ideation. San Antonio, TX: Psychological Corporation; 1991.

5. Beck A, Steer R, Brown G. Beck depression inventory-II. 1996.

6. Berlim MT, Pavanello DP, Caldieraro MAK, Fleck MPA. Reliability and validity of the WHOQOL BREF in a sample of Brazilian outpatients with major depression. Qual Life Res. 2005;14(2):561-4. doi:10.1007/s11136-004-4694-y.

7. Binder M, Coad A. Life satisfaction and self-employment: a matching approach. 2010.

8. Blanchflower DG, Oswald AJ. Is well-being U-shaped over the life cycle? 2008. doi:10.1016/j.socscimed.2008.01.030.

9. Bowden A, Fox-Rushby JA. A systematic and critical review of the process of translation and adaptation of generic health-related quality of life measures in Africa, Asia, Eastern Europe, the Middle East, South America. Soc Sci Med. 2003;57:1289-306. doi:10.1016/S0277-9536(02)00503-8.

10. Bowen R, Balbuena L, Peters E, Leuschen-Mewis C, Baetz M. The relationship between mood instability and suicidal thoughts. Arch Suicide Res. 2015; 19(2):161-71. doi:10.1080/13811118.2015.1004474.

11. Brown GK. A review of suicide assessment measures for intervention research with adults and older adults. 2001

12. Burns JK, Tomita A. Traditional and religious healers in the pathway to care for people with mental disorders in Africa: a systematic review and metaanalysis. Soc Psychiatry Psychiatr Epidemiol. 2015;50(6):867-77. doi:10.1007/ s00127-014-0989-7.

13. Chidarikire S, Harris D, Skinner I. The role of traditional and faith healers in mental health care: a meta synthesis of case reports from sub-Saharan Africa. In: Australian college of mental health nurses 40th international mental health nursing conference-honouring the past, shaping the future (Vol. 23, p. 5). 2014.

14. Chou K-L. Chronic fatigue and affective disorders in older adults: evidence from the 2007 British national psychiatric morbidity survey. J Affect Disord. 2013;145(3):331-5. doi:10.1016/j.jad.2012.08.012.

15. Cochrane-Brink KA, Lofchy JS, Sakinofsky I. Clinical rating scales in suicide risk assessment. Gen Hosp Psychiatry. 2000;22(6):445-51. doi:10.1016/S01638343(00)00106-7.

16. De Leo D, Too LS. Suicide and depression. In Okpaku S. (Ed.). Essentials of Global Mental Health. Cambridge University Press; 2014. 
17. Diener E, Suh ME. Subjective well-being and age: an international analysis. In: Annual review of gerontology and geriatrics. 1997. p. 304-24.

18. Fairweather-Schmidt AK, Batterham PJ, Butterworth P, Nada-Raja S. The impact of suicidality on health-related quality of life: a latent growth curve analysis of community-based data. J Affect Disord. 2016;203:14-21. doi:10. 1016/j.jad.2016.05.067.

19. Fortin M, Lapointe L, Hudon C, Vanasse A, Ntetu AL, Maltais D, et al. Multimorbidity and quality of life in primary care: a systematic review. Health Qual Life Outcomes. 2004;2(1):51. doi:10.1186/1477-7525-2-51.

20. Gabriel Z, Bowling A. Quality of life from the perspectives of older people. Ageing Soc. 2004;24(5):675-91. doi:10.1017/S0144686X03001582.

21. García-pérez MA, Núñez-antón V. Cellwise residual analysis in two-way contingency tables. Educ Psychol Meas. 2003;63(5):825-39.

22. Getanda EM, Papadopoulos C, Evans H, Roberts B, Damundu E, Lomoro O, et al. The mental health, quality of life and life satisfaction of internally displaced persons living in Nakuru County, Kenya. BMC Public Health. 2015; 15(1):755. doi:10.1186/s12889-015-2085-7.

23. Ghassemzadeh H, Mojtabai R, Karamghadiri N, Ebrahimkhani N. Psychometric properties of a Persian-language version of the beck depression inventory- second edition: BDI-II Persian. Depress Anxiety. 2005; 21(4):185-92. doi:10.1002/da.20070.

24. Goldney RD, Fisher LJ, Wilson DH, Cheok F. Suicidal ideation and health-related quality of life in the community. Med J Aust. 2001;175(10):546-9.

25. Han K-T, Park E-C, Kim J-H, Kim SJ, Park S, Gove W, et al. Is marital status associated with quality of life? Health Qual Life Outcomes. 2014;12(1):109. doi:10.1186/s12955-014-0109-0.

26. Hawthorne G, Herrman H, Murphy B. Interpreting the WHOQOL-BREF: preliminary population norms and effect sizes. Soc Indicators Res. 2006; 77(1):37-59. doi:10.1007/s11205-005-5552-1.

27. Hawton K, Casanas i Comabella C, Haw C, Saunders K. Risk factors for suicide in individuals with depression: a systematic review. J Affect Disord. 2013;147(1):17-28. doi:10.1016/j.jad.2013.01.004.

28. Healy DJ, Barry K, Blow F, Welsh D, Milner KK. Routine use of the beck scale for suicide ideation in a psychiatric emergency department. Gen Hosp Psychiatry. 2006;28(4):323-9. doi:10.1016/j.genhosppsych.2006.04.003.

29. Ilgen MA, Zivin K, McCammon RJ, Valenstein M. Pain and suicidal thoughts, plans and attempts in the United States. Gen Hosp Psychiatry. 2008;30(6): 521-7. doi:10.1016/j.genhosppsych.2008.09.003.

30. Jenkins R, Kiima D, Njenga F, Okonji M, Kingora J, Kathuku D, Lock S Integration of mental health into primary care and community health working in Kenya: context, rationale, coverage and sustainability. World Psychiatry. 2010;9(2):118-20.

31. Jenkins R, Othieno C, Okeyo S, Aruwa J, Kingora J, Jenkins B. Health system challenges to integration of mental health delivery in primary care in Kenya-perspectives of primary care health workers. BMC Health Serv Res. 2013;13(1):368. doi:10.1186/1472-6963-13-368.

32. Joiner TE, Walker RL. Construct validity of a measure of acculturative stress in African Americans. Psychol Assesment. 2002;14(4):462-6. doi:10.1037/ 1040-3590.14.4.462.

33. Kiima $D$, Jenkins $R$, Gureje $O$, Jenkins $R$, Jenkins $R$, McCulloch A, et al. Menta health policy in Kenya -an integrated approach to scaling up equitable care for poor populations. Int J Ment Health Syst. 2010:4(1):19. doi:10.1186/17524458-4-19.

34. Kinyanjui DW, Kathuku DM, Mburu JM, Theo P, Marieke F, Bert $P$, et al. Quality of life among patients living with epilepsy attending the neurology clinic at kenyatta national hospital, Nairobi, Kenya: a comparative study. Health Qual Life Outcomes. 2013;11(1):98. doi:10. 1186/1477-7525-11-98

35. Kohn R, Saxena S, Levav I, Saraceno B. The treatment gap in mental health care. Bull World Health Organ. 2004;82(11):858-66.

36. Kojima M, Furukawa TA, Takahashi H, Kawai M, Nagaya T, Tokudome S Cross-cultural validation of the beck depression inventory-II in Japan. Psychiatry Res. 2002;110(3):291-9. doi:10.1016/S0165-1781(02)00106-3.

37. Lamis DA, Cavanaugh CE, Anastasiades MH, Garcia-Williams A, Anderson C, Kaslow NJ. Intimate Partner Sexual Coercion Mediates the Childhood Sexual Abuse-Suicidal Ideation Link Among African American Women. J Black Psychol. 2016. doi:10.1177/0095798416644885.

38. Lindström M, Rosvall M. Marital status, social capital, economic stress, and mental health: a population-based study. Soc Sci J. 2012:49(3):339-42. doi:10.1016/j.soscij.2012.03.004.
39. Loewe N, Araya-Castillo L, Thieme C, Batista-Foguet JM. Self-employment as a moderator between work and life satisfaction. Akad Rev Latinoame Adm. 2015;28(2):213-26. doi:10.1108/ARLA-10-2014-0165.

40. Lozano R, Naghavi M, Foreman K, Lim S, Shibuya K, Aboyans V, et al. Global and regional mortality from 235 causes of death for 20 age groups in 1990 and 2010: a systematic analysis for the global burden of disease study 2010. Lancet. 2012;380(9859):2095-128.

41. Mapes DL, Lopes AA, Satayathum S, Mccullough KP, Goodkin DA, Locatelli F, et al. Health-related quality of life as a predictor of mortality and hospitalization: the dialysis outcomes and practice patterns study (DOPPS). Kidney Int. 2003;64(1):339-49. doi:10.1046/j.1523-1755.2003.00072.x.

42. Marangu E, Sands N, Rolley J, Ndetei D, Mansouri F. Mental healthcare in Kenya: exploring optimal conditions for capacity building. Afr J Prm Health Care Fam Med. 2014;6(1):1-5.

43. Masocco M, Pompili M, Vichi M, Vanacore N, Lester D, Tatarelli R. Suicide and marital status in Italy. Psychiatr Q. 2008;79(4):275-85. doi:10.1007/ s11126-008-9072-4.

44. Mbwayo A, Ndetei D, Mutiso V, Khasakhala L. Traditional healers and provision of mental health services in cosmopolitan informal settlements in Nairobi, Kenya. Afr J Psychiatry. 2013;16(2):134-40.

45. Muldoon M, Barger S, Flory J, Manuck S. What are quality of life measurements measuring? Br Med J. 1998;316(7130):542.

46. Musyimi CW, Mutiso VN, Musau AM, Matoke LK, Ndetei DM. Prevalence and determinants of depression among patients under the care of traditional health practitioners in a Kenyan setting: policy implications (in press). Transcult Psychiatry. 2015.

47. Musyimi CW, Mutiso VN, Nandoya ES, Ndetei DM. Forming a joint dialogue among faith healers, traditional healers and formal health workers in mental health in a Kenyan setting: towards common grounds. J Ethnobiol Ethnomed. 2016;12(4). doi:10.1186/s13002-015-0075-6

48. Mutimura E, Stewart A, Crowther NJ, Yarasheski KE, Cade WT. The effects of exercise training on quality of life in HAART-treated HIV-positive Rwandan subjects with body fat redistribution. Qual Life Res. 2008;17(3):377-85. doi:10.1007/s11136-008-9319-4

49. Ndetei DM, Khasakhala LI, Kuria MW, Mutiso VN, Ongecha-Owuor FA, Kokonya DA, et al. The prevalence of mental disorders in adults in different level general medical facilities in Kenya: a cross-sectional study. Ann Gen Psychiatry. 2009;8(1):1. doi:10.1186/1744-859X-8-1.

50. Ovuga E, Boardman J, Wassermann D. Prevalence of suicide ideation in two districts of Uganda. Arch Suicide Res. 2005;9(4):321-32. doi:10.1080/ 13811110500182018

51. Pinninti N, Steer RA, Rissmiller DJ, Nelson S, Beck AT. Use of the beck scale for suicide ideation with psychiatric inpatients diagnosed with schizophrenia, schizoaffective, or bipolar disorders. Behav Res Ther. 2002; 40(9):1071-9. doi:10.1016/S0005-7967(02)00002-5.

52. Power M, Bullinger M, Harper A. The World Health Organization WHOQOL100: tests of the universality of quality of life in 15 different cultural groups worldwide. Health Psychol. 1999;18(5):495-505.

53. Pyne JM, Patterson TL, Kaplan RM, Gillin JC, Koch WL, Grant I. Assessment of the quality of life of patients with major depression. Psychiatr Serv. 1997; 48(2):224-30. doi:10.1176/ps.48.2.224.

54. Ribeiro JD, Pease JL, Gutierrez PM, Silva C, Bernert RA, Rudd MD, Joiner TE. Sleep problems outperform depression and hopelessness as cross-sectional and longitudinal predictors of suicidal ideation and behavior in young adults in the military. J Affect Disord. 2012;136(3):743-50. doi:10.1016/j.jad. 2011.09.049.

55. Schuch FB, Vasconcelos-Moreno MP, Borowsky C, Zimmermann AB, Rocha NS, Fleck MP. Exercise and severe major depression : effect on symptom severity and quality of life at discharge in an inpatient cohort. J Psychiatr Res. 2015;61:25-32. doi:10.1016/j.jpsychires.2014.11.005.

56. Skevington SM, Lotfy M, O'Connell KA. The World Health Organization's WHOQOL-BREF quality of life assessment: psychometric properties and results of the international field trial. A Report from the WHOQOL Group. Qual Life Res. 2004;13(2):299-310. doi:10.1023/B:QURE.0000018486.91360.00.

57. Smith MT, Edwards RR, Robinson RC, Dworkin RH. Suicidal ideation, plans, and attempts in chronic pain patients: factors associated with increased risk. Pain. 2004;111(1):201-8. doi:10.1016/j.pain.2004.06.016.

58. Spielmans Gl, Berman MI, Linardatos E, Rosenlicht NZ, Perry A, Tsai AC, et al. Adjunctive atypical antipsychotic treatment for major depressive disorder: a meta-analysis of depression, quality of life, and safety outcomes. PLoS Med. 2013;10(3):e1001403. doi:10.1371/journal.pmed.1001403. 
59. Steer RA, Kumar G, Beck AT. Self-reported suicidal ideation in adolescent psychiatric inpatients. J Consult Clin Psychol. 1993;61(6):1096-9. doi:10.1037/ 0022-006X.61.6.1096.

60. Steptoe A, Shankar A, Demakakos P, Wardle J. Social isolation, loneliness, and all-cause mortality in older men and women. Proc Natl Acad Sci. 2013; 110(15):5797-801. doi:10.1073/pnas.1219686110.

61. Trinanes Y, Gonzalez-Villar A, Omez-Perretta CG, Carrillo-De-La-Peña MT. Suicidality in chronic pain : predictors of suicidal ideation in fibromyalgia. Pain Pract. 2015;15(4):323-32. doi:10.1111/papr.12186.

62. Ward CL, Flisher AJ, Zissis C, Muller M, Lombard C. Reliability of the beck depression inventory and the self-rating anxiety scale in a sample of south African adolescents. J Child Adolesc Ment Health. 2003;15(2):73-5. doi:10. 2989/17280580309486550.

63. Whiteford H, Degenhardt L, Rehm J, Baxter A, Ferrari A, Erskine H. Global burden of disease attributable to mental and substance use disorders: findings from the global burden of disease study 2010. Lancet. 2013; 382(9904):1575-86.

64. Wiles N, Thomas L, Abel A, Ridgway N, Turner N, Campbell J, et al. Cognitive behavioural therapy as an adjunct to pharmacotherapy for primary care based patients with treatment resistant depression: results of the CoBalT randomised controlled trial. Lancet. 2013;381(9864):375-84.

65. Woosley JA, Lichstein KL, Taylor DJ, Riedel BW, Bush AJ. Insomnia complaint versus sleep diary parameters: predictions of suicidal ideation. Suicide Life Threat Behav. 2016;46(1):88-95. doi:10.1111/sltb.12173.

66. World Health Organization. WHOQOL-BREF: Introduction, Administration, Scoring and Generic Version of the Assessment. Geneva; 1996.

67. World Health Organization. Public health action for the prevention of suicide: a framework. Geneva: World Health Organization; 2012.

68. Yao G, Chung CW, Yu CF, Taiwan W-B, Wang J-D, Yao G, et al. Development and verification of validity and reliability of the WHOQOL-BREF Taiwan version. J Formos Med Assoc. 2002;101(5):342-51.

\section{Submit your next manuscript to BioMed Central and we will help you at every step:}

- We accept pre-submission inquiries

- Our selector tool helps you to find the most relevant journal

- We provide round the clock customer support

- Convenient online submission

- Thorough peer review

- Inclusion in PubMed and all major indexing services

- Maximum visibility for your research

Submit your manuscript at www.biomedcentral.com/submit 